\title{
Mobilbruk kan skade samspillet med barn
}

Tidlig samspill mellom barn og foreldre er viktig for barnets utvikling. Redusert tilgjengelighet og avbrutt kontakt som følge av mobilbruk kan skape stress hos barnet og forstyrre relasjonen.

\section{Forfattere}

\section{Siri Amalie Hansen}

Helsesøster og psykiatrisk sykepleier

Østensjø helsestasjon

Kristine Holmen Strømsvåg

Helsesøster

Lillehammer helsestasjon

Lisbeth Valla

Helsesøster og førsteamanuensis

Institutt for sykepleie og helsefremmende arbeid, Oslomet

Nina Misvær

Helsesøster og førstelektor

Helsesøsterutdanningen HiOA

Mobil Samspill Foreldre Barn

Sykepleien 2017 105(9)(50-53)

DOI: https://doi.org/10.4220/Sykepleiens.2017.63259

\section{Hovedbudskap}

Det sosiale samspillet mellom foreldre og barn har stor betydning for barnets utvikling og tilknytning. Avbrytelser og delt oppmerksomhet med mobilbruk kan skape utfordringer. Ny nasjonal faglig retningslinje for helsestasjonen anbefaler veiledning til foreldrene ved fire uker, seks måneder, to år og fire år. Som helsesøstre argumenterer vi for å ta opp temaet tidligere og oftere. 
Tidlig samspill mellom foreldre og barn har stor betydning for barnets utvikling, både språklig, kognitivt og emosjonelt. Økende skjerm- og mobilbruk blant foreldre kan påvirke kvaliteten på samspillet, ved økt distraksjon og mindre oppmerksomhet til barnet (1).

I 2017 har 80 prosent av befolkningen smarttelefon (2). I aldersgruppen 25-44 år oppgir drøyt 95 prosent at de ofte bruker mobilen til å kople seg til internett (3). Av dem som i 2015 var på internett i løpet av en gjennomsnittlig dag, var 70 prosent innom Facebook og 44 prosent på andre sosial medier. 44 prosent hadde brukt banktjenester og 73 prosent hadde lest nyheter (4). Slik aktivitet kan ta mye tid, og dette vekker bekymring for det familiære samspill.

\section{Mangel på kunnskap}

Foreldres mobilbruk er derfor et aktuelt tema for alle som arbeider med foreldre og barn. Vi erfarer at det er mangel på kunnskap om mulige skadevirkninger for barnet og hvordan slik informasjon best kan formidles til foreldre.

Helsesøster er i kontakt med 98 prosent av alle familier. En viktig oppgave i det helsefremmende og forebyggende arbeidet på helsestasjonen er å bidra til å fremme et godt samspill mellom foreldre og barn. «Samspill i fokus» er overskriften som er blitt presentert i en ny nasjonal faglig retningslinje for helsestasjonen. Temaet samspill er anbefalt å bli tatt opp ved alle konsultasjoner.

\section{三 «Det er mangel på kunnskap om mulige skadevirkninger for barnet.»}

Temaene «Foreldrenes mobil- og skjermbruk» og «Bruk av sosiale medier» skal tas opp ved fire uker, seks måneder, to år og fire år (5). Av erfaring mener vi at temaene bør diskuteres med foreldrene allerede ved hjemmebesøket og oftere i løpet av de første levemånedene.

Faglige beslutninger skal være basert på kunnskapsbasert praksis. Dette innebærer at informasjon og veiledning til foreldrene skal bygge på forsknings- og erfaringsbasert kunnskap i tillegg til brukererfaringer. Vi har grunn til å tro at når foreldrene kjenner til bakgrunnen for informasjonen vi formidler, så vil de regulere bruk av mobiltelefon i samvær med barnet sitt. 


\section{Tidlig samspill}

Med tidlig samspill menes samspill mellom foreldre og barn i første leveår. Dette omhandler overføring av informasjon, regulering av atferd og følelse av samhørighet.

I samspillet vil foreldrene og barnet ha et felles mål om interaksjon og kommunikasjon. Barn har kapasitet til å inngå i sosial kommunikasjon med andre mennesker allerede fra fødselen. Omsorgspersonene vil være spesielt betydningsfulle i den første tiden. Bare en time gammel kan barnet etterlikne forelderen og ta del i en dialogliknende kommunikasjon. Barnet imiterer den voksne ved for eksempel å rekke tunge, gape og etterlikne ansiktsuttrykk (6). Spedbarnets kapasitet til å respondere og ta initiativ i samspill vil gradvis øke. Ved to ukers alder vil spedbarnet kunne kommunisere med lyder og bevegelser.

\section{Fellesskap}

Ansikt-til-ansikt-kommunikasjon mellom foreldre og barn er svært viktig i et samspill. I tidlig samspillsfase får foreldre og barn en umiddelbar fornemmelse av fellesskap med følelsesmessig synkronisering og veksling med å gi og motta kontakt.

Gjensidigheten betyr at ikke bare foreldrene følger spedbarnets rytme og kommunikasjon, men at barnet også kan registrere den voksnes tilstand og følelsesuttrykk, blant annet gjennom å lese og tolke den voksnes ansikt og kroppsspråk. Barnets kapasitet til en slik deltakelse vises allerede kort tid etter fødsel (7).

Ved tre måneders alder vil barnet også kunne gi et mer aktivt uttrykk og positiv affekt rettet mot omsorgsgiver. Ved økende alder vil samspillet kunne foregå over lengre tidssekvenser, og barnet vil kunne kommunisere med smil, gester og vokalisering (8). Ved åtte, ni måneders alder vil samspillet også dreie seg om felles oppmerksomhet på objekter i omgivelsene ved at oppmerksomhet ledes ved å peke, lage lyd eller bruke gester som utgangspunkt for kommunikasjon og samtale (9).

\section{Emosjonelt tilgjengelige}


Forskning har vist at spedbarn er sosialt kompetente individer fra fødselen av, men for at utviklingen skal forløpe normalt, er de helt avhengige av at omsorgspersonene er emosjonelt tilgjengelige, både sensitivt og bekreftende.

Sensitivitet kan forstås som omsorgspersonens tendens til å oppfatte og nøyaktig tolke barnets signaler og reaksjonstendenser, for deretter å respondere på riktig måte så raskt som mulig. Begrepet emosjonell tilgjengelighet blir brukt for å beskrive både omsorgspersonens og barnets atferd i en relasjonell kontekst $(10,11)$.

Det såkalte «Still-face»-eksperimentet (11) viser nettopp hvor sensitive spedbarn er overfor den affektive kvaliteten på samspillet. Her deltok sju spedbarn i alderen en til fire måneder. Omsorgspersonen fikk instruks om å «bryte samspillet» og unnlate å reagere på signaler fra barnet med et ubevegelig «steinansikt». Mødrenes fraværende respons førte til stresset atferd hos barna. Gjentakende og langvarig stress kan påvirke hjernens utvikling hos barn som er særlig mottakelige og formbare for spesielle erfaringer og læring i de første leveårene (12).

Hjernens sensitivitet i spedbarnsalder gir store muligheter for læring, men øker samtidig sårbarheten for uheldig utvikling (13). Kvaliteten på tidlig samspill antas dermed å ha betydning for barns videre utvikling når det gjelder regulering av følelser og tilknytning til omsorgspersoner.

\section{Øker stressnivået}

Nyere forskning har tatt eksperimentet videre ved at de observerte barnets reaksjoner underveis. Funn viser at barnet tok mindre initiativ i interaksjon, smilte sjeldnere og begynte å gråte raskere når forelderen ikke responderte. Ved avbrutt respons, økte barnets stressnivå, som var størst i fasen der barnet og forelderen skulle gjenopprette kontakten (14).

\section{三Ansikt-til-ansikt-kommunikasjon mellom foreldre og barn er svært viktig.»}


NRK viste en liknende sekvens i et TV-program i fjor (15) der mors utilgjengelighet for barnet skyldtes bruk av mobiltelefon. De tre barna som deltok, viste de samme reaksjoner som spedbarna i «Still face»-eksperimentet (15). Med tanke på avbrutt samspill og manglende blikkontakt har altså «Still face»-eksperimentet fellestrekk med foreldres samspill med barnet når de bruker mobiltelefon.

\section{Foreldres holdninger}

Studier kan dokumentere den indirekte påvirkning som mobil- og skjermbruk kan ha på foreldre-barn-interaksjonen $(16,17,18)$. Mindre oppmerksomhet og respons fra foreldrene kan påvirke samspillet.

Mobilbruk vil også ta konsentrasjonen bort fra barnet. Foreldrenes oppmerksomhet blir delt, og tilgjengeligheten blir mindre. Følgene kan bli mindre ansikt-til-ansiktinteraksjon, samt mindre sosial og fysisk tilstedeværelse i samspill med barnet.

Oppsummert forskning fra 27 studier viste at foreldres holdning og bruk av mobiltelefon hadde stor betydning for samspillet med barnet (19). Mødre som var opptatt med mobiltelefonen, responderte mindre på barnets signaler og hadde mindre verbal og nonverbal kommunikasjon. Respons og sensitivitet i samspillet var dårligere sammenliknet med mødre med mindre mobilbruk.

\section{Mat og stell}

En av studiene (19) viste at mødres bruk av mobiltelefon under måltider kunne påvirke barnets matsituasjon og rutiner. Mating og stell er eksempler på anledninger for god interaksjon hvor man kan være synkront med barnet.

\section{三 «Dialogen om mobilbruk med foreldrene bør gjentas regelmessig.»}

Barn av mødre som hyppigere brukte mobiltelefon, var også mer utsatt for ulike risikosituasjoner som for eksempel å klatre på bord (20, 21). Slik kan det synes som foreldres mobilbruk representerer både en psykisk og fysisk risikofaktor for barns helse, tilsvarende «Still face»eksperimentet. Liknende studier er oss kjent ikke utført i Norge eller Skandinavia, men vi kan anta at samme resultat også vil kunne bli funnet her. 


\section{Helsesøsters praksis}

Utstrakt mobilbruk hos foreldre kan være uheldig for samspill med barnet. Brudd i samspill og manglende kommunikativ respons kan påvirke barnet (22). På bakgrunn av erfaringer og funn fra studier om samspillets betydning for barnets utvikling, foreslår vi altså at temaet tas opp både tidligere og oftere enn det den nye retningslinjen fra Helsedirektoratet anbefaler (5).

Ikke alle helsestasjoner tilbyr gruppekonsultasjon (barselgruppe) ved fire ukers alder og/eller barnet kan ha rukket å bli opp mot tre måneder før det blir gjennomført. Erfaringsmessig er det på langt nær alle mødre som møter opp til denne konsultasjonen, og det er sjelden at fedre deltar.

Vi ønsker derfor at mobiltelefon og samspillstematikken tas opp allerede på hjemmebesøket som er anbefalt gjennomført når barnet er sju til ti dager, og hvor fedre oftest har mulighet for å delta. Ved dette første møtet samtaler helsesøster om barnets temperament og initiativ til kontakt (5). Det er hensiktsmessig å samtidig fortelle om grunnleggende samspillsfaktorer som blikkontakt, bruk av stemme, ulike ansiktsuttrykk, god berøring og dialogliknende kommunikasjon mellom barnet og foreldrene.

\section{Egne erfaringer}

Hvilke erfaringer foreldrene selv har i kontakten med barnet sitt, er et godt utgangspunkt for samtalen, samtidig med refleksjon over mellommenneskelige relasjoner og hvordan samvær de ønsker med sitt barn. Det at foreldrene selv setter ord på sine tanker om egen mobilbruk, vil trolig ha bedre effekt enn at helsesøster forteller dem hva hun mener at de bør gjøre.

\section{三 «Gjentakende og langvarig stress kan påvirke hjernens utvikling.»}


Helsesøsters formidling av kunnskap om temaet kan bidra til at foreldrene blir bedre i stand til å ta hensiktsmessige valg. Dialogen om mobilbruk med foreldrene bør gjentas regelmessig det første leveåret for å sikre at et godt samspill blir ivaretatt fra barna er ganske små. Disse første konsultasjonene er nære i tid, og helsesøster får anledning til å følge opp samtalen fra forrige gang, fordi foreldrene gis mulighet til å reflektere over temaet i mellomtiden. Fedre bør oppfordres til å delta på konsultasjonene på helsestasjonen deres bidrag i samspillet har stor betydning for barnets utvikling (23).

\section{Reduser bruken}

Hva er for mye mobil? Dette er uvisst. Barn tåler brudd i samspill uten at dette gir varige skader, men utstrakt mobilbruk kan være urovekkende da bruddene vil være både hyppige og mer omfattende. Dette vil kunne påvirke barnets interaksjon på en måte som på sikt kan være skadelig for barnet.

Vi har i dag ikke tilstrekkelig kunnskap om foreldres mobilbruk og påvirkning på samspillet, men vi har pålitelig kunnskap om at hyppige brudd i interaksjonen mellom foreldre og barn ikke er gunstig for et godt samspill (14).

Barns evne til å regulere stress er ikke ferdig utviklet, og barns stressreaksjon aktiveres lettere enn hos voksne. Stress er ugunstig i en sensitiv periode for hjernens utvikling. Stress er også lite gunstig der tidlig samspill skal etableres (24).

Denne kunnskapen er vesentlig å dele med foreldrene. Helsesøster kan oppfordre foreldrene til å iverksette enkle regler og innarbeide gode vaner som kan fungere for dem. Noen klarer å legge mobiltelefonen helt bort mens barnet er våkent og unngår da usikkerhet om hva som er for mye mobilbruk. For helsesøster er det viktig å støtte foreldrene i at all redusert bruk av mobiltelefon er et gode.

\section{Mobilfri sone}

Barselavdelinger og helsestasjoner henger opp oppslag som tydeliggjør et ønske om mobilfri sone. Samtidig synes problematikken å være lite omtalt av fagfolk i møtet med familiene. Foreldrenes mobilbruk sammen med barnet er ikke nødvendigvis skadelig i seg selv, men det kan være en risikofaktor for barnets utvikling. 
Dersom foreldrenes mobilbruk er av en slik hyppighet og karakter at det stadig blir avbrudd i kontakten med barnet, kan dette få negative konsekvenser for barnets helse. På bakgrunn av eksisterende kunnskapsgrunnlag bør fagfolk som jobber med sped- og småbarnsfamilier bidra med kunnskap og refleksjon rundt utfordringene knyttet til hvordan mobilbruk kan påvirke samspillet med barnet.

Helsesøstre har for eksempel anledning til å ta opp mobilbruk med alle foreldre allerede på hjemmebesøket og også ved konsultasjonene når barnet er seks uker og tre måneder gammelt, i tillegg til de anbefalte alderstrinnene fire uker, seks måneder, to år og fire år (5).

\section{Referanser:}

1. Kirkorian HL, Pempek TA, Murphy LA, Schmidt MA, Anderson DA. The impact of background television on parent-child interaction. Child Dev. 2009;80(5):1350-59.

2. MedieNorge. Andel som har smarttelefon; 2017.

Tilgjengelig fra:

http://www.medienorge.uib.no/statistikk/medium/ikt/379

(nedlastet 01.09.17)

3. Statistisk sentralbyrå. Bruk av IKT i husholdningene, 2016,

2. Kvartal; 2016. Tilgjengelig fra:

https://www.ssb.no/teknologi-og-

innovasjon/statistikker/ikthus/aar (nedlastet 16.05.17.)

4. Statistisk sentralbyrå. Norsk mediebarometer 2015; 2016.

Tilgjengelig fra: https://www.ssb.no/kultur-og-

fritid/statistikker/medie/aar/2016-04-14 (nedlastet 01.09.17.)

5. Helsedirektoratet. Nasjonal faglig retningslinje for det helsefremmende og forebyggende arbeidet i helsestasjon, skolehelsetjeneste og helsestasjon for ungdom; 2017.

Tilgjengelig fra:

https://helsedirektoratet.no/retningslinjer/helsestasjons-ogskolehelset... (nedlastet 17.09.17)

6. Simpson EA, Murray L, Paukner A, Ferrari PF The mirror neuron system as revealed through neonatal imitation: presence from birth, predictive power and evidence of plasticity. Philosophical transactions of the royal society 2014. DOI: 10.1098/rstb.2013.0289 
7. Trevarthen C. The foundations of intersubjectivity:

Development of interpersonal and cooperative understanding in infants. I: The social foundations of language and thought. New York: W.W. Norton; 1980 (s. 316-42).

8. Lavelli M, Fogel, A. Developmental changes in the relationship between the infant's attention and emotion during early face-to-face communication: the 2-month transition. Developmental psychology 2005; 41(1):265.

9. Trevarthen C, Hubley P. Secondary intersubjectivity:Confidence, confinding and acts og meaning in the firstyear. I: A Lock A. (red). Action, gesture and symbol. The emergence of language. London: Academic Press; 1978.

10. Cohn JF, Tronick EZ. Three-month-old infants' reaction to simulated maternal depression. Child development 1983; 54(1):185-93.

11. Tronick EZ, Als H, Adamson L, Wise S, Brazelton T. The infant`s response to entrapment between contradictory messages in face-to-face interaction. Journal of the American Academy of Children and Adolescent Psychiatry 1978; 17: 113.

12. Berg-Nielsen TS. Tidlig stress og senere helseurovekkende sammenhenger. I: Holme H, Olavesen, E S, Valla L, Hansen M B (red.). Helsestasjonstjenesten: barns psykiske helse og utvikling. Oslo: Gyldendal Akademisk; 2016.

13. Tamnes CK. Hjerneutvikling fra fosterlivet til voksen alder. Tidlige faktorer og erfaringers betydning. I: Holme H, Olavesen ES, Valla L, Hansen M B. (red.)

Helsestasjonstjenesten: barns psykiske helse og utvikling. Oslo: Gyldendal akademiske; 2016.

14. Ekas NV, Haltigan JD, Messinger DS. The Dynamic StillFace Effect: Do Infants Decrease Bidding Over Time When Parents are Not Responsive? Dev. Psychol 2012. DOI: 10.1037/a0029330 
15.NRK-viten. Hva skjer med babyen din når du gir oppmerksomheten til mobilen? Tilgjengelig fra:

https://tv.nrk.no/serie/teknologien-som-forandreross/DMPV73001116/seson... (nedlastet 16.10.16.)

16. Anderson DR, Hanson KG. Screen media and parentchild interactions. I: Media Exposure During Infancy and Early Childhood. Springer International Publishing; 2017 (s. 173-94).

17. McDaniel BT, Coyne SM. Technology interference in the parenting of young children: Implications for mothers' perceptions of coparenting. The Social Science Journal 2016. DOI: 10.1016/j.soscij.2016.04.010

18. Ventura, AK, Teitelbaum S. Maternal distraction during breast-and bottle feeding among WIC and non-WIC mothers. Journal of Nutrition Education and Behavior 2017; 49(7):169-76.

19. Kildare CA, Middlemiss W. Impact of Parents Mobile Device Use on Parent-Child Interaction: A Literature Review. Computers in Human Behavior 2017; 75: 579-593.

20. Radesky J, Miller AL, Rosenblum KL, Appugliese D, Kaciroti N, Lumeng JC. Maternal mobile devise use during a structured parent-child interaction task. Academic Pediatrics 2014. DOI: 10.1016/j.acap.2014.10.001.

21. Radesky JS, Christakis DA. Increased screen time: Implications for early childhood development and behavior. Pediatric Clinics of North America 2016; 63(5): 827-39. DOI: http://dx.doi.org/10.1016/j.pcl.2016.06.006

22. Braarud HC. Kompleks traumatisering hos barn: En utviklingspsykologisk forståelse. Tidsskrift for Norsk psykologforening, 2011; 48 (10): 968-72.

23. Skjøthaug, T Fedres rolle i barnets tidlige utvikling. I: Holme, H, Olavesen ES, Valla L, Hansen MB. (red.) Helsestasjonstjenesten: barns psykiske helse og utvikling. Oslo: Gyldendal; 2016. 
24. Braarud HC, Nordanger DØ. Når vold og overgrep infiltrerer omsorgen for små barn. I: Holme H, Olavesen ES, Valla L, Hansen, MB. (red). Helsestasjonstjenesten: barns psykiske helse og utvikling. Oslo: Gyldendal akademiske; 2016. 